\title{
La reforma universitaria desde el Estado y el radicalismo estudiantil nicolaita, 1926-1935 ${ }^{1}$
}

\author{
The university reform from the State and the Nicolaita student radicalism, \\ 1926-1935
}

A reforma universitária desde o Estado e o radicalismo estudantil Nicolaíta, 1926-1935

\author{
Miguel Ángel Gutiérrez López ${ }^{2}$ \\ Universidad Michoacana de San Nicolás de Hidalgo (México)
}

Recepción: 20/05/2017

Evaluación: 13/09/2017

Aceptación: 05/01/2018

Artículo de investigación - Reflexión

DOI: https://doi.org/10.19053/01227238.8024

\section{RESUMEN}

El artículo hace referencia a un proceso de reforma universitaria que tuvo lugar en los años veinte y treinta en Michoacán. En particular, se abordan los rectorados de Jesús Díaz Barriga y Enrique Arreguín Vélez, dos de los dirigentes socialistas más importantes de la época. También se hace alusión a otros personajes como Natalio Vázquez Pallares, quien al igual que Arreguín transitó rápidamente del liderazgo estudiantil al gobierno universitario. Una característica de estos universitarios fue su cercanía con el general Lázaro Cárdenas, gobernador de Michoacán y presidente de la República en esos años.

Uno de los propósitos del texto es mostrar la participación de las organizaciones estudiantiles en un proceso de reforma universitaria que planteó el establecimiento de una Universidad de Estado. En esta labor coincidieron agrupaciones estudiantiles y autoridades universitarias, con el apoyo de los gobiernos estatal y federal. Las primeras desempeñaron un papel relevante como instrumentos de propaganda ideológica y de control social.

El grado de radicalización política e ideológica de las organizaciones estudiantiles socialistas ayudó a acelerar y profundizar la implementación de la política educativa oficial en Michoacán y otros lugares del país. Agrupaciones como el Consejo Estudiantil Nicolaita y el Bloque de Jóvenes Revolucionarios de Michoacán combatieron sistemáticamente a los adversarios políticos e ideológicos del cardenismo, lo que les dio un lugar privilegiado dentro de la estructura universitaria.

Palabras clave: Revista Historia de la Educación Latinoamericana; Reforma de la

1 Artículo de investigación científica y tecnológica. Resultado del proyecto de investigación, Control y disidencia. Movilizaciones y organizaciones estudiantiles en la Universidad Michoacana, 1917-1963, realizado con el apoyo de la Coordinación de la Investigación Científica de la Universidad Michoacana de San Nicolás de Hidalgo.

2 Doctor en Historia por El Colegio de Michoacán. Profesor e investigador de la Facultad de Historia de la Universidad Michoacana de San Nicolás de Hidalgo. Miembro del Cuerpo Académico de Historia de México, CA-48. Miembro del Sistema Nacional de Investigadores, nivel 2. Correo electronico: manglar21@gmail.com 
educación; movimiento estudiantil; organización de estudiantes; participación estudiantil; Universidad, México.

\begin{abstract}
The article refers to a process of university reform that took place in the 1920s and 1930s in Michoacán. We specially focus on the rectorates of Jesús Díaz Barriga and Enrique Arreguín Vélez, two of the most important socialist leaders of that time. Other characters such as Natalio Vázquez Pallares, who, as well as Arreguín, ascended quickly from the student leadership to the university leadership. A common characteristic among these university students was their closeness to General Lázaro Cárdenas, Governor of Michoacán and President of the Republic in those years. One of the purposes of this paper is to show the participation of student organizations in a process of the university reform that proposed the establishment of a State University. For this purpose, student groups and university authorities joined forces with the support of the state and federal governments. The former played an important role as instruments of ideological propaganda and social control. The degree of political and ideological radicalization of the socialist student organizations helped to accelerate and deepen the implementation of the official educational policy in Michoacán and other places in the country. Groups such as the Nicolaita Student Council and the young revolutionaries block of Michoacan systematically fought against the political and ideological opponents of Cardenismo, which gave them a privileged place within the university structure.

Keywords: Journal History of Latin American Education; education reform; student movement; student organization; student participation; University; Mexico.
\end{abstract}

\section{RESUMO}

O artigo faz referência a um processo de reforma universitária que teve lugar nos anos vinte e trinta em Michoacán. Especificamente, se abordam os reitorados de Jesús Díaz Barriga e Enrique Arreguín Vélez, dois dos dirigentes socialistas mais importantes da época. Também fazemos alusão a outras personagens, como Natalio Vázquez Pallares, quem, da mesma forma que Arreguín, transitou rapidamente da liderança estudantil ao governo universitário. Uma característica desses universitários foi a proximidade com o general Lázaro Cárdenas, governador de Michoacán e presidente da República nesse período. Um dos propósitos do texto é mostrar a participação das organizações estudantis em um processo de reforma universitária que planejou o estabelecimento de uma universidade de Estado. Neste esforço, coincidiram grupos de estudantes e autoridades universitárias, com o apoio dos governos estatal e federal. As primeiras desempenharam um papel relevante como instrumentos de propaganda ideológica e de controle social. O grau de radicalização política e ideológica das organizações estudantis socialistas contribuiu para acelerar e aprofundar a implementação da política oficial em Michoacán e outros lugares do país. Agrupamentos como o Conselho Estudantil Nicolaíta e o Bloco de Jovens Revolucionários de Michoacán combateram sistematicamente os adversários políticos e ideológicos do cardenismo, o que lhes garantiu um lugar privilegiado dentro da estrutura universitária.

Palavras-chave: Revista História da Educação Latino-americana, Reforma da educação, movimento estudantil, organização de estudantes, Participação estudantil, Universidade, México. 


\section{INTRODUCCIÓN}

Entre 1926 y 1935 es posible ver el crecimiento y consolidación de un proceso de reforma universitaria en Michoacán. Los límites de este proyecto van más allá de este marco temporal, pero en esos años ocurrieron acontecimientos que hicieron visibles algunas de sus características más importantes. En 1926 inició el rectorado de Jesús Díaz Barriga y en 1935 ocupó ese cargo Enrique Arreguín Vélez, dos de los principales líderes socialistas de la época. Junto a estas figuras también destacó Natalio Vázquez Pallares quien encabezó el gobierno universitario algunos años después. Estos dirigentes, junto a otros nicolaitas, colaboraron estrechamente con las administraciones estatal y federal de Lázaro Cárdenas. Ideológicamente se asumieron como cardenistas y socialistas y estuvieron integrados al partido oficial.

En el proyecto de reforma universitaria socialista, que planteó el establecimiento de una Universidad de Estado, confluyeron organizaciones estudiantiles y autoridades universitarias que apoyaron la política educativa pública. Las organizaciones estudiantiles socialistas promovieron la política anticlerical de los gobiernos de la época. También desempeñaron un papel importante como instrumentos de propaganda ideológica y control social, por medio de misiones culturales y campañas antialcohólicas y desfanatizadoras. En el terreno político, se propusieron como estrategia garantizar el control del estudiantado a partir de los principios del "socialismo" oficial.

El radicalismo socialista fue atemperado por las líneas de acción marcadas por el proyecto político cardenista. Los nicolaitas asumieron el laicismo, el anticlericalismo, la socialización de la educación y de las profesiones, como parte de un programa que reconoció el papel rector del Gobierno de la República. El radicalismo de los universitarios cardenistas nunca puso en entredicho el poder del Estado. En la práctica, cumplieron una función estratégica al combatir sistemáticamente a sus adversarios ideológicos y políticos. Las purgas ideológicas y el control de las organizaciones estudiantiles fueron muestra de ello.

Este artículo ha sido construido a partir de fuentes de primera mano en las que están expuestas las ideas y posturas de los universitarios michoacanos. Esta documentación fue complementada con otra de carácter oficial que contiene la posición institucional, tanto de la Universidad Michoacana como del Estado mexicano en los años veinte y treinta. De manera paralela, fueron utilizados los resultados de investigaciones que en los años recientes han propuesto claves para la interpretación del tema expuesto.

\section{La universidad cardenista}

El médico Jesús Díaz Barriga asumió la rectoría de la Universidad Michoacana de San Nicolás de Hidalgo en julio de 1926. Se mantuvo en el cargo hasta 1932, lo que constituyó un caso excepcional de estabilidad en la administración 
universitaria, caracterizada por los constantes cambios en su conducción. Los últimos cuatro años de su rectorado coincidieron con la administración estatal de Lázaro Cárdenas (1928-1932), un gobernante con el que se identificó un gran número de universitarios. ${ }^{3}$ Esta relación continuó cuando este asumió la Presidencia de la República en 1934 e incorporó a algunos nicolaitas a su equipo de trabajo.

Lázaro Cárdenas estableció mecanismos de comunicación directa con la Universidad Michoacana y sus miembros. En reciprocidad, profesores y alumnos de la institución apoyaron el programa educativo gubernamental y constituyeron una base social de apoyo para el mandatario michoacano. Fue en esos momentos en que un amplio sector de los universitarios que se asumían como revolucionarios y socialistas terminaron por definirse como cardenistas, con lo que en la práctica los términos "cardenista" y "socialista" terminaron siendo casi sinónimos.

La propuesta de una reforma educativa, que formaba parte del programa político cardenista, fue apoyada y enriquecida por los universitarios michoacanos. De esta colaboración surgieron proyectos y acciones que tuvieron como finalidad la aplicación de un modelo educativo que, bajo la guía del Estado, buscaría "socializar" la enseñanza. Las autoridades universitarias y las principales organizaciones estudiantiles se plegaron a la línea política e ideológica sostenida por el Ejecutivo estatal y compartieron sus postulados.

Las propuestas de "socializar" la enseñanza promovidas por los universitarios michoacanos durante la gubernatura de Lázaro Cárdenas habían tenido un antecedente en el inicio de los años veinte. Durante el rectorado de Ignacio Chávez, que coincidió con la gestión de Francisco J. Múgica como gobernador del estado (1920-1922), se realizaron importantes modificaciones en la estructura y legislación universitarias. El Ejecutivo estatal aumentó sus atribuciones en lo referente a la conducción de la casa de estudios y se reforzó el carácter laico de la enseñanza. También debe considerarse que Múgica llegó a la gubernatura postulado por el Partido Socialista Michoacano. ${ }^{4}$

Durante la gestión cardenista, el interés del Ejecutivo estatal por la enseñanza superior se expresó de manera directa en sus esfuerzos por ampliar la oferta educativa de la Universidad Michoacana. El 31 de diciembre de 1929, en una reunión de directores de planteles universitarios con representantes gubernamentales, se informó que el Gobierno del estado estaba dispuesto a patrocinar la creación de una Escuela de Ingeniería, sostenida por las autoridades estatales, para que no se afectaran los recursos destinados a las demás dependencias universitarias. La propuesta fue discutida y aprobada por los miembros del Consejo Universitario en enero de 1930; ese mismo año fue establecido el plantel. ${ }^{5}$

3 Adrián Luna Flores, La Universidad Michoacana: 1926-1932. El rectorado de Jesús Díaz Barriga (Morelia: UMSNH, 2002). Ángel Gutiérrez Martínez, Lázaro Cárdenas y la Universidad Michoacana (Morelia: UMSNH, 2005).

4 Véase: Pablo G. Macías, Aula Nobilis (México: Ediciones Vanguardia Nicolaita, 1940), 399-427.

5 "Acta de Consejo Universitario" (Morelia, 4 de enero de 1930), Archivo Histórico de la Universidad Michoacana (AHUM), Consejo Universitario, Secretaría, Actas. Lázaro Cárdenas, Palabras y documentos públicos de Lázaro Cárdenas, 1928-1970. Informes de gobierno y mensajes presidenciales de año nuevo, 1928-1940 (México: Siglo XXI Editores, 1978), 15. 
Al hacer un balance de su administración, Lázaro Cárdenas expuso planteamientos en los que coincidió con los universitarios. En el informe de labores correspondiente a su periodo gubernamental hizo una crítica al laicismo por considerar que dejaba a los padres la libertad de inculcar a sus hijos "las modalidades espirituales" de mayor arraigo en los hogares e impedía la posibilidad de "unificar las conciencias hacia el fin por el cual [luchaba] la Revolución". El Ejecutivo también propuso la unidad en los programas escolares y atacó la existencia de planteles educativos privados por considerar que debido a su "espíritu conservador o retardatario" neutralizaban la acción del Estado. En lo que respecta a la educación superior, el gobernador Lázaro Cárdenas señaló que era la Universidad la institución a la que correspondía la formación de los individuos directores del Estado. ${ }^{6}$

\section{El interludio serratista}

La salida de Jesús Díaz Barriga de la rectoría de la Universidad Michoacana y la llegada a la gubernatura del estado del general Benigno Serrato, ${ }^{7}$ enemigo político del cardenismo, alteraron las relaciones de cooperación que se habían establecido entre un amplio sector de universitarios y las autoridades estatales. La designación de Gustavo Corona como rector de la casa de estudios dividió a los universitarios. Por un lado, se colocaron aquellos identificados con el cardenismo y que se asumían a sí mismos como "socialistas" y, por otro, las nuevas autoridades universitarias, apoyadas por el Ejecutivo estatal. Esta situación generó una serie de movilizaciones y manifestaciones de rechazo a la labor del Consejo Universitario y llevó a la Universidad Michoacana a enfrentar, en 1933, la primera huelga de grandes dimensiones de su historia.

La llegada de Gustavo Corona a la rectoría de la Universidad Michoacana rompió la hegemonía que los socialistas habían ejercido en la institución. La administración serratista, a través del secretario general de Gobierno, Victoriano Anguiano, terminó con el control socialista y promovió la llegada de una nueva dirigencia universitaria. Anguiano invitó a colaborar con la Universidad Michoacana a antiguos compañeros suyos, provenientes de la máxima casa de estudios del país y formados políticamente en las filas del vasconcelismo, entre los que se encontraban Manuel Moreno Sánchez, Rubén Salazar Mallén y Ernesto Carpy Manzano. ${ }^{8}$

Las actividades de este grupo no se limitaron a la administración y las aulas universitarias, sino que se extendieron al gobierno del estado. Las nuevas autoridades trajeron consigo su propio proyecto de institución. El rector y sus

6 Lázaro Cárdenas, óp. cit., 27-28, 30.

7 El general Benigno Serrato fungió como gobernador de la entidad entre el 16 de septiembre de 1932 y el 3 de diciembre de 1934 , fecha en que falleció en un accidente de aviación. La administración de Serrato se distinguió por su enfrentamiento con los sectores identificados con el cardenismo.

8 Victoriano Anguiano Equihua, Lázaro Cárdenas. Su feudo y la política nacional (México: Editorial Referencias, 1989), 78. Verónica Oikión Solano, Los hombres del poder en Michoacán, 1924-1962 (Zamora: El Colegio de Michoacán, UMSNH, 2004$), 150$. 
colaboradores, con el apoyo del Ejecutivo estatal, buscaron cambiar el rumbo de la Universidad, modificando su normatividad y transformando las prácticas administrativas, políticas y académicas que regían en su interior. Para lograr este objetivo plantearon la necesidad de redefinir las relaciones de la Universidad con el poder público, otorgando a los universitarios un mayor poder de decisión, e impulsaron la promulgación de una nueva ley orgánica. Estas medidas serían la causa del enfrentamiento con los universitarios "socialistas", quienes buscaron recuperar el control de la institución. Estas pugnas fueron potenciadas por la campaña que en 1933 emprendió Lázaro Cárdenas por alcanzar la presidencia de la República y que animó a sus simpatizantes a desafiar a los grupos adictos al gobernador Serrato.

Durante 1933 tuvieron lugar diversos enfrentamientos y un movimiento de huelga sin que los socialistas lograran recuperar el control de la Universidad. Estos conflictos mostraron las profundas diferencias en torno a la idea de Universidad que tenían los grupos antagónicos. Finalmente, la aparente derrota del movimiento huelguista de 1933 se transformó en victoria un año después. La trágica muerte del gobernador Benigno Serrato y el ascenso a la Presidencia de la República del general Lázaro Cárdenas modificaron el panorama político estatal. En el nuevo escenario, los "socialistas" michoacanos tomarían el control de la Universidad y renovarían su compromiso con el poder.

\section{El estudiantado socialista organizado}

En la segunda mitad de los años veinte, las agrupaciones estudiantiles más importantes dentro de la Universidad Michoacana eran el Consejo Estudiantil Nicolaita (CEN) y la Federación de Estudiantes Michoacanos (FEM). Ambas organizaciones, creadas durante el rectorado de Ignacio Chávez y la gubernatura de Francisco J. Múgica, aglutinaban a la mayoría del estudiantado organizado en la institución. En el Comité Ejecutivo de la FEM en 1926 se encontraban figuras que destacarían en la política estatal y nacional en los años siguientes como, Gabino Vázquez y Enrique Arreguín Vélez.

A lo largo de los años veinte, los estudiantes consolidaron su posición dentro de la Universidad a través del fortalecimiento de la estructura de sus agrupaciones, pero fue hacia el final de la década que se empezó a perfilar la posibilidad de agrupar a todo el alumnado universitario en una sola organización. Con este objetivo, el 27 de mayo de 1930 se realizó, en el Colegio de San Nicolás, el Primer Congreso Local de Estudiantes Universitarios, en el que se discutió la formación de una federación estudiantil de alcance estatal. ${ }^{9}$ En el congreso participaron el CEN y las sociedades de alumnos de la Escuela de Comercio, la Facultad de Medicina, la Escuela de Bellas Artes, la Escuela de Ingeniería y la Sociedad Revolucionaria de Estudiantes Michoacanos de Jurisprudencia. ${ }^{10}$

9 "Educación Preparatoria" (AHUM), UMSNH, CEN, libro 137.

10 Adrián Luna Flores, La Universidad Michoacana: 1926-1932. El rectorado de Jesús Díaz Barriga (Morelia: UMSNH, 2002 ), 56. 
Tras casi una década de existencia, el CEN se había consolidado como la organización estudiantil mejor estructurada y con mayor peso y proyección políticos. Como cuadros dirigentes empezaron a figurar elementos que destacaron por sus dotes de líderes estudiantiles. Rápidamente, la agrupación se convirtió en la instancia formadora y promotora de los principales cuadros políticos dentro del ámbito universitario. El proyecto de crear una federación de estudiantes universitarios de Michoacán no se concretó en 1930, por lo que el CEN mantuvo e incrementó su preeminencia. En ese momento ocupaba su presidencia Natalio Vázquez Pallares, quien destacaría como dirigente estudiantil a nivel nacional en los años posteriores y llegaría a ser rector de la Universidad Michoacana en 1939. Vázquez Pallares fue electo presidente definitivo del CEN el 2 de junio de 1930. Hasta ese momento desempeñaba el cargo de manera interina. ${ }^{11}$ Como una muestra del poder que iba adquiriendo la organización, puede señalarse que, en noviembre de 1930, su dirigencia pidió a las autoridades del Colegio de San Nicolás que se permitiera a la agrupación la designación de los profesores que a su juicio deberían hacerse cargo de las clases en el plantel. ${ }^{12}$

En algunas dependencias universitarias se formaron agrupaciones estudiantiles autocalificadas como "revolucionarias". Entre estas destacaron la anteriormente mencionada Sociedad Revolucionaria de Estudiantes Michoacanos de Jurisprudencia, así como la Asociación Revolucionaria de Alumnos de la Escuela de Comercio, creada en agosto de 1931. De acuerdo con sus integrantes, esta agrupación tendría como objetivo contrarrestar la acción de la sociedad de alumnos del plantel, por considerar que no correspondía a las "tendencias revolucionarias" que requería el momento. Los miembros de la organización se plantearon llevar a cabo la localización y sanción de los estudiantes considerados "retardatarios". A los miembros de la asociación se les exigiría "cierto grado de actividad física y mental debajo de la cual se [consideraría] nocivo cualquier individuo". Además, se señaló que sería estimado dañino cualquier estudiante que mostrara normas de conducta opuestas a las "tendencias revolucionarias" que sustentaban el programa de la asociación, en especial las inspiradas en "doctrinas confesionales". También serían considerados peligrosos los alumnos afectados por padecimientos contagiosos, los cuales serían segregados de la Escuela de Comercio por el tiempo en que permanecieran enfermos. ${ }^{13}$

En agosto de 1932, se hizo un nuevo intento por unificar al estudiantado michoacano. El 22 de ese mismo mes inició sus actividades una convención estudiantil convocada por el CEN, en la que se presentaron propuestas para constituir y poner en funciones la Unión Estudiantil Michoacana. Con ese fin se nombró una comisión especial para redactar los estatutos de la organización, pero en las discusiones sobre el asunto se enfrentaron dos posturas sobre el ca-

11 "Educación Preparatoria" (AHUM), UMSNH, CEN, libro 137, f. 1031.

12 Información posterior sugiere que recibieron una respuesta favorable por parte de las autoridades universitarias. "Educación Preparatoria", AHUM, UMSNH, CEN, libro 137, f. 1095.

13 "Programa de acción de la Asociación Revolucionaria de Alumnos de la Facultad de Comercio", (AHUM), UMSNH, Educación Profesional, Escuela de Comercio, caja 112. 
rácter de la misma. Un sector proponía que la organización tuviera un carácter clasista, mientras que otro abogaba por dar cabida al colaboracionismo. ${ }^{14}$ Los miembros del primer grupo hicieron valer su posición y presentaron un proyecto de estatutos para crear la Unión de Estudiantes Socialistas de Michoacán (UESM), la cual sería una agrupación exclusivamente estudiantil, con sede en el Colegio de San Nicolás. ${ }^{15}$

Otra organización relevante en esa época fue el Partido Nacional Estudiantil Pro Cárdenas (PNEC). Su creación tuvo lugar en julio de 1933, en Morelia, con la fusión de 25 organizaciones estudiantiles del país. Natalio Vázquez Pallares fue el coordinador de la reunión, Carlos Madrazo fue el secretario general y Lauro Ortega fue nombrado secretario general del partido. Siguiendo con esta línea política y una vez que se cumplió con el objetivo de promover la candidatura presidencial de Lázaro Cárdenas, en agosto del año siguiente, se conformó la Confederación de Estudiantes Socialistas de México (CESM). Carlos Madrazo fue el presidente del comité organizador que se reunió en julio con la asistencia de 226 delegados. La junta directiva de la reunión estuvo integrada por Madrazo, como presidente, y Natalio Vázquez Pallares, como primer secretario. Una de las tareas de la CESM fue la creación de entidades similares por todo el país. Como parte de esta estrategia surgió en diciembre de 1934, el Frente de Estudiantes Socialistas de Occidente, en Guadalajara, bajo la dirección de Natalio Vázquez Pallares y Rodolfo González. ${ }^{16}$

El Segundo Congreso de la CESM se realizó en Uruapan, Michoacán. En este lugar se reunieron algunos de los jóvenes dirigentes socialistas más destacados y con mayor futuro político: Natalio Vázquez Pallares, Carlos Madrazo, Jesús Robles Martínez, Enrique Ramírez y Ramírez, Juan Gil Preciado, L. Darío Vasconcelos, Fernando Román Lugo, Ángel Veraza, entre otros. Las conclusiones de la reunión fueron, luchar por la reforma del artículo tercero constitucional y por la implantación de la educación socialista en todos los niveles de enseñanza. ${ }^{17}$

Natalio Vázquez Pallares fue parte de un grupo de jóvenes que, en la política nacional, se formó más allá de las movilizaciones estudiantiles, integrándose a la estructura del Partido Nacional Revolucionario (PNR) como parte del cardenismo en los momentos en los que estaba por definirse el Primer Plan Sexenal y la postulación de Cárdenas a la Presidencia de la República. En ese grupo de jóvenes políticos en ascenso estaban Carlos Madrazo, Gilberto Suárez Torres y Norberto Aguirre Palancares. ${ }^{18}$

El PNEC tuvo una larga vida, aunque con otras denominaciones. Al concluir la campaña presidencial y hasta su segunda convención en 1935, se transformó en Juventudes Socialistas de México. Después de ese congreso pasó a denomi-

\footnotetext{
14 Anónimo, "La convención estudiantil empezó sus labores", Juventud (Morelia, 26 de agosto de 1932): 1.

15 Anónimo, "Proyecto de Estatutos de la Unión de Estudiantes Socialistas de Michoacán presentada por la Comisión de Estatutos de la Convención Estudiantil", Juventud (Morelia, 26 de agosto de 1932), 5-6.

16 Rogelio Hernández Rodríguez, La formación del político mexicano. El caso de Carlos A. Madrazo (México: El Colegio de México, UJAT, 1997), 28, 36-37.

17 Íbid., 37-38.

18 Íbid., 34-35.
} 
narse Juventudes Socialistas Unificadas de México. Con esa denominación se mantuvo hasta la creación de la Confederación de Jóvenes Mexicanos en 1939.19

En mayo 1934 se conformó el Bloque de Jóvenes Revolucionarios de Michoacán (BJRM), una organización que sería determinante para la Universidad en los años siguientes. El Bloque se creó a instancias de la CRMDT con el propósito de reunir a la "juventud radical revolucionaria" de la capital del estado para que actuara en toda la entidad realizando una labor de preparación de los trabajadores. ${ }^{20} \mathrm{Su}$ creación estuvo inspirada en el programa de acción del Bloque de Jóvenes Revolucionarios de Tabasco (BJRT). Tras un viaje a Tabasco, en el que acompañaron a Lázaro Cárdenas, Jesús Díaz Barriga y Enrique Arreguín expresaron en la prensa, en abril de 1934, su admiración por Tomás Garrido Canabal. Los visitantes quedaron impresionados por el Bloque por lo que decidieron replicar la experiencia en Michoacán. ${ }^{21}$

En Tabasco se crearon organizaciones que apoyaron las campañas de desfanatización. Entre estas destacaron la Liga de Maestros Ateos, La Liga Anticlerical y el BJRT. Las actividades de este grupo trascendieron las fronteras del estado y persiguieron sacerdotes en Chiapas. También tuvieron presencia en la Ciudad de México en actos antirreligiosos. El BJRT fue el resultado de algunos ensayos anteriores para la conformación de grupos de choque. En 1924 ya existían cuerpos selectos de las ligas de resistencia, llamados Voluntarios de Tabasco, que más tarde pasaron a denominarse Vanguardia Revolucionaria. ${ }^{22}$

El BJRT fue organizado en 1931 por el gobernador de Tabasco, Tomás Garrido Canabal. Esta agrupación sirvió como guardia personal, así como vehículo de difusión de medidas radicales contra la religión y el alcoholismo. El BJRT fue conocido como los "Camisas Rojas", por la indumentaria que utilizaban: pantalón negro, camisa roja, corbata negra. Este grupo fue organizado por el Partido Radical Socialista Tabasqueño y auspiciado por el gobierno del estado. El Bloque fue creado como resultado de las labores de un Congreso Anticlerical que se realizó en 1931 en la Ciudad de México. Entre ese año y 1934 sus miembros actuaron casi exclusivamente en Tabasco. Posteriormente, llegaron a la capital del país cuando Tomás Garrido Canabal se integró al primer gabinete cardenista como Secretario de Agricultura. En diciembre de 1934 comenzaron a realizar los denominados Sábados Rojos en el Palacio de Bellas Artes de la Ciudad de México. Estas actividades incluían actos culturales diversos y discursos radicalmente anticlericales. Ese mismo mes, el extremismo de los Camisas Rojas llegó a un límite intolerable para el gobierno federal y empezó su declive. El destino de los

19 Íbid., 28.

20 Anónimo, "Estatutos y programa de acción del Bloque de Jóvenes Revolucionarios de Michoacán”, Gremio (Morelia, 20 de diciembre de 1934), 3-4. Anónimo, "Congreso de estudiantes. El Bloque de Jóvenes Revolucionarios Michoacanos lo celebra en Morelia”, El Nacional (México, 26 de abril de 1935).

21 Véase: Ma. de la Paz Hernández Aragón, Juan Hernández Luna. Humanista nicolaita del siglo XX (Morelia: UMSNH, 2001), 29-30. Carlos Domingo Méndez Moreno, "El Bloque de Jóvenes Revolucionarios de Michoacán y la política social cardenista" (Tesis de maestría. Universidad Michoacana de San Nicolás de Hidalgo. Michoacán, 2008), 101-110.

22 Rogelio Hernández Rodríguez, La formación del político mexicano. El caso de Carlos A. Madrazo (México: El Colegio de México, UJAT, 1997), 21. Carlos Domingo Méndez Moreno, El anticlericalismo en Tabasco: entre prácticas, símbolos y representaciones (Morelia: UMSNH, 2016), 86 . 
Camisas Rojas se selló con la salida de Garrido del primer gabinete cardenista en junio de 1935. Ese año cesaron las actividades de la agrupación, coincidiendo con el declive político del exmandatario tabasqueño. ${ }^{23}$

En Michoacán, el BJRM no se condujo con la violencia de su similar tabasqueño, pero compartió características como el anticlericalismo y la intolerancia hacia otras corrientes ideológicas. En el ámbito educativo, los lineamientos generales que el BJRM estimaba que deberían regir en la universidad fueron presentados en 1934 por Jesús Díaz Barriga y Enrique Arreguín a través de un documento titulado, Proyecto sobre la nueva organización educativa universitaria de acuerdo con la tesis del socialismo científico. ${ }^{24} \mathrm{El}$ Proyecto fue dado a conocer profusamente por el BJRM. La propuesta recibió la atención de la prensa nacional y fue enviada, en septiembre, a manera de memorial, a la Cámara de Diputados federal. ${ }^{25}$ Ese mismo mes, la iniciativa fue dada a conocer al Consejo Universitario bajo la premisa de que la Universidad Michoacana, como sus similares del país, tenía una estructura "anticuada liberalista" que no había tomado en cuenta el cambio económico y social generado por la Revolución, por lo que se hacía imperativo imprimir un nuevo carácter a la educación superior. ${ }^{26}$

De manera paralela a la propuesta de dar un carácter socialista a la Universidad Michoacana, promovida por el BJRM, las autoridades de la institución empezaron a discutir el tema, pero a partir de una premisa diferente. En este caso, fue la inminente reforma del artículo $3^{\circ}$ constitucional lo que llevó a que el 23 de octubre de 1934 la Universidad Michoacana fuera declarada socialista por acuerdo del Consejo Universitario. ${ }^{27}$

\section{El radicalismo nicolaita}

Los universitarios michoacanos participaron en la política anticlerical implementada por los gobiernos federal y estatal. Los nicolaitas asumieron las campañas desfanatizadoras y el enfrentamiento entre la Iglesia y el Estado como parte esencial de su programa político y de su esfuerzo por implantar su ideal educativo en la Universidad Michoacana. Las purgas ideológicas y la persecución en contra de los detractores de la educación laica y socialista se volvieron una constante como forma de garantizar el control sobre el estudiantado.

En mayo de 1926 un grupo de estudiantes, integrantes del CEN, solicitó, a través del Ejecutivo del estado, que el Templo de la Compañía de Jesús les fue-

23 Íbid., (1997)18-19, 39, 41.

24 Enrique Arreguín Vélez y Jesús Díaz Barriga, "Proyecto sobre la nueva organización educativa universitaria de acuerdo con la tesis del socialismo científico", en Enrique Arreguín Vélez: su pensamiento y acción en la ciencia y en la cultura (Morelia: UMSNH, 1968), 183-213.

25 Anónimo, "Michoacán inicia la educación socialista", Excelsior, 22 de septiembre, 1934. Anónimo, "El deber de la Universidad", El Nacional, 23 de septiembre, 1934. Anónimo, "La Universidad debe dar sus frutos para el pueblo y no para la clase parasitaria. Memorial del Bloque de Jóvenes Revolucionarios Michoacanos a la Cámara", El Nacional, 22 de septiembre, 1934.

26 "Comunicación del BJRM al rector y a los miembros del Consejo Universitario de la Universidad Michoacana", (Morelia, 14 de septiembre de 1934), Archivo Particular de Enrique Arreguín Vélez (APEAV), caja 44.

27 "Acta de Consejo Universitario" (Morelia, 23 de octubre de 1934), (AHUM), Consejo Universitario, Secretaría, Actas. 
ra cedido para utilizarlo como biblioteca pública y sala de conferencias para la instrucción de grupos obreros. ${ }^{28}$ La propuesta fue apoyada por algunos universitarios de la Facultad de Jurisprudencia, entre quienes se encontraba Alberto Bremauntz. ${ }^{29}$ Las gestiones tuvieron éxito y el Templo de la Compañía fue cedido a la Universidad Michoacana por el presidente de la República, Plutarco Elías Calles, por medio de un acuerdo expedido el 31 de mayo de $1926 .{ }^{30}$

Algunos universitarios católicos externaron públicamente su oposición a la decisión del Ejecutivo federal. Esta situación llevó a que, el 11 de agosto de 1926, se presentara a la consideración del Consejo Universitario un oficio de la dirigencia del CEN en el que se pedía la expulsión definitiva de un grupo de 19 alumnos acusados de haber incitado, mediante una hoja volante, a los maestros y estudiantes a mostrar su desacuerdo con que el Templo de la Compañía pasara al dominio de la Universidad. Se aseguró que los acusados obraban influenciados por sacerdotes católicos y desarrollaban actividades anticonstitucionales y antiestudiantiles; también se les imputó haber desconocido públicamente a las autoridades del Gobierno de la República y de la Universidad Michoacana. ${ }^{31}$

El regente del Colegio de San Nicolás, Porfirio García de León, se mostró partidario de la expulsión definitiva de los estudiantes acusados; sin embargo, el rector Jesús Díaz Barriga propuso que esta medida tuviera carácter temporal por no sentirse con el derecho de tener en sus manos el destino de una persona. Alberto Bremauntz pidió que se les expulsara por tres años, debido a que tenía la impresión de que los alumnos señalados difícilmente cambiarían su manera de pensar, sin importar el tipo de castigo que se les impusiera. Bremauntz destacó la necesidad de aplicar un castigo ejemplar que sentará un precedente para casos posteriores, ante el temor de que alumnos de otras escuelas siguieran el ejemplo de los estudiantes del Colegio de San Nicolás. Para apoyar esta propuesta informó que en la Escuela de Comercio un grupo de alumnos, pertenecientes a la Asociación Católica de la Juventud Mexicana, se había organizado para redactar un documento en apoyo de los estudiantes que se trataba de castigar. Por estas razones, pidió la expulsión de los inculpados al considerar que su actitud formaba parte de la labor desarrollada por los defensores de la libertad religiosa con el objetivo de iniciar un movimiento contrario a la posición del Gobierno. ${ }^{32}$

La asamblea sometió a votación el castigo que debía imponerse a los acusados. Por un lado, estaba la propuesta de expulsión definitiva y por el otro la idea de que una suspensión temporal era más que suficiente para sentar un precedente. Tras dos rondas, la votación estaba empatada por lo que el rector

28 Anónimo, "Solicitud de los estudiantes nicolaitas", Ariel, Morelia, 15 de mayo, 1926, 1-3.

29 Alberto Bremauntz (1897-1978) egresó de la Escuela de Jurisprudencia de la Universidad Michoacana en 1929. Como diputado federal participó activamente en la reforma del artículo $3^{\circ}$ constitucional de diciembre de 1934 que dio sustento a la educación socialista. Fue rector de la Universidad Michoacana de agosto de 1963 a agosto de 1966. Hilda Díaz Aldama, Los estudios de jurisprudencia en la Universidad Michoacana, 1917-1932 (Morelia: UMSNH, 2000), 121-123.

30 Adrián Luna Flores, La Universidad Michoacana: 1926-1932. El rectorado de Jesús Díaz Barriga (Morelia: UMSNH, 2002), 66-69.

31 "Acta de Consejo Universitario" (Morelia 11 de agosto de 1926), (AHUM), Consejo Universitario, Secretaría, Actas.

32 "Acta de Consejo Universitario" (Morelia 11 de agosto de 1926), (AHUM), Consejo Universitario, Secretaría, Actas. 
intervino con su voto de calidad decretándose la expulsión definitiva de un grupo de once alumnos. ${ }^{33}$

Un par de años después, en junio de 1932, un grupo de estudiantes, entre los que se encontraba Natalio Vázquez Pallares, dio a conocer un manifiesto en el que expresaron su apoyo a la reglamentación del número de ministros de culto. En esta ocasión, los firmantes del documento, que concluía con la frase "por la liberación espiritual de las masas", contaron con el apoyo de un Comité de Salud Pública de Michoacán. ${ }^{34}$

En enero de 1934, un Comité de Depuración Estudiantil hizo pública una acusación contra los alumnos del segundo año de secundaria, de quienes se decía estaban constituidos en su mayoría por fanáticos católicos y algunos protestantes. El comité hizo notar que un grupo de estudiantes de ese grado de secundaria hacía profesión de fe católica y estaba desarrollando una labor de propaganda dentro del Colegio para engrosar las filas de una asociación de estudiantes católicos dependiente del Seminario de Morelia. Se señaló que esos elementos se habían infiltrado en la Universidad provenientes del Seminario y de la Escuela Libre. Esta institución se había convertido en la principal institución antagonista de la Universidad Michoacana, por ser un plantel que defendía los intereses de sectores católicos que impugnaban la política educativa oficial. A su vez, a los grupos protestantes se les acusó de promover sus doctrinas y de ser individuos provenientes de escuelas dirigidas por pastores extranjeros. ${ }^{35}$

El 4 de enero de 1935, el agente del Ministerio Público Federal, Alberto Cano, informó al presidente de la República, Lázaro Cárdenas, haber tomado posesión del edificio donde había funcionado la Escuela Libre, al tiempo que pidió que el edificio fuera cedido a la Universidad Michoacana. ${ }^{36}$ Esta acción fue realizada a instancias del Ejecutivo del estado y ratificada por el presidente de la República mediante un decreto expropiatorio. ${ }^{37}$ La Universidad cerró este ciclo con el simbólico acto de establecer un Centro Cultural Obrero en el edificio en el que había funcionado la desaparecida escuela.

\section{La Universidad socialista en 1935}

La muerte del gobernador Benigno Serrato, el 3 de diciembre de 1934, y la llegada a la primera magistratura estatal del general Rafael Sánchez Tapia abrieron la posibilidad de un cambio en la administración universitaria. El deceso de Serrato y la renuncia del rector Gustavo Corona generaron la movilización de

\footnotetext{
33 "Acta de Consejo Universitario" (Morelia 11 de agosto de 1926), (AHUM), Consejo Universitario, Secretaría, Actas.

34 "Manifiesto de los estudiantes nicolaitas al pueblo de Michoacán” (Morelia, 19 de junio de 1932), (APNVP), caja 1.

35 "La lacra social encarnada en los alumnos del segundo año de secundaria del Colegio de San Nicolás de Hidalgo" (Morelia, 30 de enero de 1934), (APEAV), caja 38.

36 "Telegrama de Cano al presidente de la República” (Morelia, 4 de enero de 1935), Archivo General de la Nación (AGN), Lázaro Cárdenas del Río (LCR), caja 745, exp. 534.8/3.

37 "Telegrama del gobernador del Estado de Michoacán al presidente de la República” (Morelia, 5 de enero de 1935), (AGN), LCR, caja 687, exp. 534/10. Anónimo, "Decreto por el que se destina al servicio del Gobierno del Estado, el predio número 580 de la Avenida Madero, en Morelia, Michoacán”, Diario Oficial, México, 1 de febrero, 1935, 2.
} 
los sectores "socialistas" que habían quedado marginados de la conducción de la Universidad desde 1932.

El 7 de diciembre de 1934, un grupo denominado Comité de Estudiantes Socialistas Pro Reorganización Universitaria expuso al nuevo gobernador del estado su posición ante el relevo en la rectoría. Enterados de la renuncia presentada por Corona manifestaron al mandatario la necesidad de que el nombramiento del nuevo rector se hiciera de manera democrática, tomando en cuenta la opinión del sector estudiantil. Por esta razón, externaron la decisión de apoyar la designación de Enrique Arreguín Vélez como candidato a la rectoría universitaria. ${ }^{38}$

El Comité de Estudiantes Socialistas Pro Reorganización Universitaria fue creado con el fin único de designar al candidato de la organización a la rectoría. El comité se ostentaba como la agrupación que había logrado unificar el criterio de un conjunto de organizaciones que decían luchar por la implantación de una Universidad de Estado. Estas agrupaciones eran el BJRM, el Sindicato de Obreros Intelectuales de Michoacán, la Federación Agraria del Norte, organizaciones ligadas a la Confederación Revolucionaria Michoacana del Trabajo (CRMDT), así como estudiantes independientes. ${ }^{39}$

Enrique Arreguín fue nombrado rector y asumió el cargo el 15 de diciembre de $1934{ }^{40}$ con el compromiso de llevar a la práctica los planes del BJRM de dar carácter socialista a la Universidad Michoacana. ${ }^{41}$ En enero del año siguiente, en el discurso que dio al inaugurar el año lectivo, Arreguín ratificó lo expuesto en el Proyecto sobre la nueva organización educativa universitaria de acuerdo con la tesis del socialismo científico, que meses atrás había presentado en colaboración con Jesús Díaz Barriga. La ceremonia de inicio de cursos, efectuada el 15 de enero, devino en un acto proselitista en el que se dio a conocer la posición ideológica de las nuevas autoridades universitarias y sus aliados políticos. Participaron oradores en representación de los sectores estudiantil y de profesores. También hubo intervención del magisterio michoacano, del BJRM, de la CRMDT y del secretario general de Gobierno, en representación del gobernador del estado. ${ }^{42}$

En su discurso, Enrique Arreguín dejó ver la necesidad de impulsar una selección y depuración del personal docente, llevando a las aulas a profesores comprometidos con el "movimiento socialista", al que se consideraba que aspiraba la Revolución Mexicana. Con relación al plan de trabajo de la Universidad para el año de 1935, destacó de manera especial la labor que desarrollaría la institución con los núcleos organizados de obreros y campesinos. ${ }^{43}$

38 "Memorial dirigido al gobernador del estado, Rafael Sánchez Tapia, por el Comité de Estudiantes Socialistas Pro Reorganización Universitaria" (Morelia, 7 de diciembre de 1934), (AGN), LCR, caja 745, exp. 534.8/3.

39 "Acta constitutiva del Comité de Estudiantes Socialistas Pro Reorganización Universitaria”, (AGN), LCR, caja 745, exp. 534.8/3.

40 Anónimo, "Nuevo rector", Gremio, Morelia, 20 de diciembre, 1934, 1.

41 "Oficio del BJRM al presidente de la República, Lázaro Cárdenas”, (AGN), LCR, caja 745, exp. 534.8/3.

42 Anónimo, "Solemne inauguración de cursos en la Universidad. Fue delineado el programa a los trabajadores", brecha, Morelia, jueves 17 de enero, 1935, 1, 4 .

43 Enrique Arreguín Vélez, Enrique Arreguín Vélez: su pensamiento y acción en la ciencia y en la cultura (Morelia: UMSNH, 1968), 225226. 
La educación de los trabajadores fue, en el discurso y en la práctica, uno de los elementos más importantes del proyecto de Universidad socialista. En los hechos, esta idea se tradujo en la organización de actividades y campañas instructivas y moralizantes dirigidas a los trabajadores del campo y la ciudad. Misiones culturales, campañas antialcohólicas, actividades de desfanatización, festivales artísticos, conferencias, competencias deportivas, fueron algunos de los medios por los que los universitarios se propusieron extender el alcance de sus actividades más allá de los límites de la institución. Estas labores estuvieron acompañadas de la creación de una dependencia universitaria especializada en la educación de los trabajadores: el Centro Cultural Obrero.

El Centro Cultural Obrero, creado con el objetivo de atender a obreros, campesinos y empleados públicos, abrió sus inscripciones el 5 de enero de 1935 y fue inaugurado un mes después. ${ }^{44}$ Los recursos para su funcionamiento, pago de profesores y gastos diversos, fueron suministrados a la Universidad Michoacana gracias a un acuerdo con el presidente de la República, mediante una aportación mensual de 346 pesos. Este apoyo permitió a la Universidad realizar actividades de extensión universitaria sin desviar recursos de su presupuesto. ${ }^{45}$

Para 1935, la propuesta de asignaturas a impartir y los profesores estuvo conformada por: Enrique Arreguín, educación sexual; Jesús Díaz Barriga, historia general; Alberto Oviedo Mota, historia de la Revolución Mexicana; Luis Marín Pérez, economía política; José Zavala Alcaraz, historia de los sistemas sociales; Jesús Ortega C., legislación obrera y agraria; Jesús Ramírez M., derecho usual y organización social; J. Jesús Múgica, cooperativismo y organización de cooperativas. ${ }^{46}$ Sin embargo, este plan no se aplicó en su totalidad debido a diversas circunstancias, como el retraso en la asignación de recursos económicos y al poco interés que despertaron algunas de las materias. En septiembre de 1935 se suprimieron las clases de legislación agraria, economía política e historia de la Revolución Mexicana debido a la escasa o nula asistencia a las mismas. En contraparte, se señaló que los trabajadores preferían las clases prácticas como taquigrafía, electricidad, mecanografía y educación primaria. ${ }^{47}$ En 1935 el Centro Cultural Obrero contó con una inscripción de 268 alumnos, pero el promedio de asistencia fue de 173. Además de las actividades docentes, en el centro se realizaron 56 festivales, 31 conferencias sobre temas científicos, 42 conferencias sobre temas sociales, 19 proyecciones cinematográficas, 3 exposiciones de carteles revolucionarios. Los festivales tuvieron una asistencia promedio de cerca de 200 personas. $^{48}$

44 Anónimo, "Un centro cultural para obreros. Ha sido fundado por el rector de la Universidad Michoacana", Brecha, Morelia, miércoles 9 de enero, 1935, 1-4. Anónimo, "El ‘Centro Cultural Obrero’ fue inaugurado en la ex Escuela Libre de Michoacán”, El Nacional, México, 10 de febrero, 1935.

45 "Corte de caja que practica la Universidad Michoacana de San Nicolás de Hidalgo, por los ingresos y egresos habidos durante el mes de abril [y mayo] del presente año [1935], con relación a los fondos que ministra el C. Presidente de la República, para sostenimiento del Centro Cultural Obrero Nocturno, dependiente de dicha institución" (Morelia, 4 de mayo de 1935), (AGN), LCR, caja 692, exp. $534.1 / 92$.

46 "Nóminas del personal del Centro Cultural Obrero" (México, febrero y marzo de 1935), (AGN), LCR, caja 692, exp. 534.1/92.

47 "Acta de Consejo Universitario" (Morelia, 10 de septiembre de 1935), (AHUM), Consejo Universitario, Secretaría, Actas.

48 Anónimo, "Labor de la Universidad en 1935. La acción organizadora del Centro Cultural Obrero", El Nacional, México, 18 de enero, 
En lo que a los estudios profesionales respecta, el proyecto de Universidad socialista se ajustó a los planteamientos del Plan Sexenal en la materia, que estableció la intención de no aumentar el número de profesionistas liberales, ya que se consideró más urgente el fortalecimiento del sistema educativo rural y la ampliación y perfeccionamiento de las escuelas técnicas. ${ }^{49}$ Las autoridades universitarias, en conjunto con las autoridades estatales y federales, propusieron el fortalecimiento y la creación de estudios dirigidos a satisfacer necesidades concretas. Entre éstas destacaron las relacionadas con el fomento de la educación primaria, con la planeación económica y social, y con las actividades derivadas de las reformas de carácter agrario. En este esfuerzo, los estudios médicos, la enseñanza normal y la formación de ingenieros recibieron una atención especial por medio de la reorganización de las dependencias encargadas de esas labores, así como por la adquisición de instrumentos y material de trabajo mediante compras y donaciones de las autoridades estatales y federales.

Como parte de la reorganización de los estudios profesionales, en febrero de 1935, el rector Arreguín propuso en el Consejo Universitario la creación de las carreras de licenciado en economía y en ciencias sociales. Sin embargo, esta propuesta lejos de significar un crecimiento en la oferta educativa de la Universidad implicaba la apertura de los estudios de economía a costa de la clausura de los cursos de Derecho, por considerarse que no respondían a las necesidades sociales del momento. ${ }^{50}$

El proyecto maduró y, en agosto de 1935, Arreguín informó al presidente de la República la apertura, en el próximo ciclo escolar, de la carrera de economista. Para sustentar la decisión se destacó la importancia que podrían tener estos estudios en la planeación y organización social. ${ }^{51}$ En respuesta y atendiendo a la petición de las autoridades universitarias, la Secretaría de Economía Nacional designó a dos profesores para impartir cursos sobre economía y organizar el plan de estudios respectivo. ${ }^{52}$ Como resultado de estos trabajos, el 6 de octubre de 1935 fue discutido y aprobado, por el Consejo Universitario, el proyecto de plan de estudios para la Escuela de Economía. ${ }^{53}$

Los estudios normalistas también recibieron atención especial por parte de las autoridades universitarias. La Escuela Normal volvió al seno de la Univer-

1936.

49 Lázaro Cárdenas, Plan Sexenal del PNR (México: PNR, 1934), 89.

50 “Acta de Consejo Universitario" (Morelia, 1 de febrero de 1935), (AHUM), Consejo Universitario, Secretaría, Actas.

51 "Comunicación del rector de la Universidad Michoacana, Enrique Arreguín Jr., al presidente de la República, Lázaro Cárdenas" (Morelia, 17 de agosto de 1935), (AGN), LCR, caja 681; exp. 533/28.

52 “Comunicación del rector de la Universidad Michoacana, Enrique Arreguín Jr., al presidente de la República, Lázaro Cárdenas" (Morelia, 20 de septiembre de 1935), (AGN), LCR, caja 681; exp. 533/28.

53 "Acta de Consejo Universitario" (Morelia, 6 de octubre de 1935), (AHUM), Consejo Universitario, Secretaría, Actas. Aunque todo parecía marchar bien en los planes para establecer la nueva escuela, las cosas cambiaron con la salida de Enrique Arreguín de la rectoría. Las autoridades universitarias dieron marcha atrás en el proyecto y el Consejo Universitario tomó el acuerdo de mantener los estudios de Jurisprudencia y limitar los estudios de Economía al establecimiento de algunos cursos y conferencias sobre el tema dentro de la Facultad de Derecho. "Comunicación de un grupo de alumnos de la Facultad de Derecho de la Universidad Michoacana al presidente de la República, Lázaro Cárdenas” (Morelia, 9 de diciembre de 1935), Archivo del Centro de Estudios sobre la Revolución Mexicana "Lázaro Cárdenas" (ACERMLC), Francisco J. Múgica (FJM), caja 2, exp. 121, doc. 3. "Acta de Consejo Universitario" (Morelia, 8 y 20 de enero de 1936), (AHUM), Consejo Universitario, Secretaría, Actas. 
sidad Michoacana, en 1935, después de haber permanecido fuera de su control y presupuesto desde 1930. Esta situación generó cambios tanto en la legislación educativa en el estado, como en la orientación docente y en la estructura de la propia escuela.

En el aspecto presupuestario, la Universidad Michoacana inició 1935 con un grave problema económico que obligó a sus autoridades a gestionar una mayor aportación de recursos por parte de los gobiernos estatal y federal. Con esta finalidad, una comisión especial se trasladó a la Ciudad de México para solicitar al presidente de la República la asignación de fondos extraordinarios. De manera paralela, Enrique Arreguín logró, a través del Ejecutivo estatal, que el Museo Michoacano, el Laboratorio Biológico y la Biblioteca Pública pasaran a depender económicamente del municipio de Morelia, pero siguieran bajo la administración universitaria. ${ }^{54}$

El apoyo económico concedido por los gobiernos estatal y federal a la Universidad Michoacana fue una muestra de la relación que se había establecido entre los universitarios michoacanos y el poder público. A partir de 1935, el presupuesto universitario fue complementado con una partida especial proveniente del Gobierno federal, la cual representó ese año un subsidio de 35 mil pesos. ${ }^{55}$ Además, en varias ocasiones y con diferentes motivos, los universitarios se dirigieron al presidente de la República para solicitar apoyo para llevar a cabo sus actividades, encontrando respuestas favorables a sus peticiones.

La Universidad Michoacana también se involucró en la realización de actividades que aglutinaron a diversos sectores de la izquierda a nivel estatal y nacional. En octubre de 1935 se efectuó en Uruapan el Segundo Congreso Nacional de Estudiantes Socialistas, con una participación destacada de los universitarios michoacanos, tanto en la organización como en el desarrollo de los trabajos. El acto inaugural, realizado el 8 de octubre, fue presidido por Jesús Díaz Barriga, en representación del presidente de la República, y contó con la presencia del rector Enrique Arreguín, en calidad de invitado de honor por parte del Comité Ejecutivo Nacional de la CESM. ${ }^{56}$ El congreso contó con la asistencia de representaciones de todos los estados del país, con excepción de los estudiantes de San Luis Potosí. El rector Arreguín presentó la ponencia, “Bases para la creación de la Universidad Socialista de Estado". ${ }^{57}$

\section{La oposición radical al socialismo universitario}

La gestión de Enrique Arreguín al frente de la Universidad Michoacana duraría un año, pero en este periodo trataría de poner en práctica el proyecto de

54 "Acta de Consejo Universitario" (Morelia, 1 de febrero de 1935), (AHUM), Consejo Universitario, Secretaría, Actas.

55 En 1935 la cantidad otorgada por las autoridades federales a la Universidad Michoacana fue de 35 mil pesos, aumentando hasta llegar a 50 mil en 1937. María Teresa Vizcaíno López, Universidad Michoacana de San Nicolás de Hidalgo: panorama jurídico, 19171939 (Morelia: UMSNH, 2000), 122-124.

56 "Oficio del Comité Ejecutivo Nacional de la CESM al rector de la Universidad Michoacana, Enrique Arreguín Vélez" (México, 19 de septiembre de 1935), (APEAV), caja 18, exp. 1, f. 134.

57 Anónimo, "Se inauguró el II Congreso de Estudiantes Socialistas", El Nacional, México, 10 de octubre, 1935, 1- 10. 
Universidad socialista esbozado desde principios de la década. La actividad, en este sentido, sería intensa en algunos rubros y provocaría cambios en la organización y actividades universitarias.

Las medidas adoptadas por la nueva administración universitaria estuvieron sustentadas en el peso político de las organizaciones partidarias del rector Arreguín y en el apoyo directo del Ejecutivo estatal y de la Presidencia de la República. No obstante, a pesar de su aparente fortaleza, la Universidad socialista enfrentó las críticas de algunos sectores universitarios, incluidos aquéllos identificados con las posturas más radicales dentro de la izquierda del momento.

Desde su llegada a la rectoría, Enrique Arreguín tuvo que enfrentar constantes muestras de indisciplina por parte de estudiantes que ostentaban abiertamente su desacuerdo con la gestión de la nueva administración universitaria. Una de esas manifestaciones de descontento tuvo lugar en febrero, cuando un grupo de alumnos denunció la negativa de las autoridades para comprar algunos libros que consideraban necesarios para su formación. Los inconformes señalaron que las autoridades universitarias realizaban gastos superfluos, mientras se negaban a erogar 100 pesos en la adquisición de materiales indispensables para la educación de los universitarios. Entre los libros demandados estaban El Capital, de Carlos Marx, El Anti Düring, de Federico Engels y Materialismo Histórico, de Bujarin. ${ }^{58}$

En mayo de 1935 tuvieron lugar una serie de hechos que despertaron alarma entre las autoridades universitarias. El día 12, durante los actos conmemorativos de la muerte de Isaac Arriaga, un grupo de estudiantes lanzó ataques contra las autoridades universitarias. Días después, un grupo de estudiantes de la Escuela Secundaria número 7, "Josefa Ortiz de Domínguez", de la Ciudad de México, fue recibido a pedradas en la estación de ferrocarril de Morelia. Estos hechos se repitieron el 21 de mayo, durante un encuentro deportivo entre los estudiantes invitados y alumnos del Colegio de San Nicolás, con saldo de varios estudiantes y profesores heridos. En los disturbios, el prefecto del Colegio de San Nicolás fue agredido y lanzado a una de las fuentes de la Plaza de Armas. Los ataques provocaron la retirada de los profesores y estudiantes invitados, quienes se entrevistaron con el gobernador del estado para informarle lo ocurrido. Posteriormente, antes de partir hacia la Ciudad de México, los afectados se reunieron con el rector Arreguín quien en nombre de la Universidad les ofreció una disculpa. ${ }^{59}$

El 22 de mayo, ante el Consejo Universitario, Arreguín señaló que los acontecimientos habían tenido su origen en la labor de agitación de algunos elementos "pseudocomunistas", a los que calificó de disolventes, que aprovechaban cualquier ocasión para causar desórdenes. Los elementos señalados también fueron acusados de atacar a los gobiernos estatal y federal, y de publicar algunos panfletos anónimos en los que insultaban a profesores y autoridades universitarias. ${ }^{60}$

58 Anónimo, "Las autoridades universitarias dicen que no hay dinero", Atalaya, Morelia, 1 de marzo, 1935, 1. Anónimo, "Ya llegaron los libros a la Biblioteca del Colegio de San Nicolás", Atalaya, Morelia, 1 de abril, 1935, 1.

59 "Acta de Consejo Universitario" (Morelia, 22 de mayo de 1935), (AHUM), Consejo Universitario, Secretaría, Actas.

60 "Acta de Consejo Universitario" (Morelia, 22 de mayo de 1935), (AHUM), Consejo Universitario, Secretaría, Actas. 
Las autoridades universitarias estuvieron de acuerdo en castigar a los alumnos señalados como agitadores, pero las posiciones se dividieron entre los que proponían la expulsión temporal y los que pensaban que debería ser definitiva; finalmente, se decidió expulsarlos por el resto del año escolar y el siguiente. Al anunciar esta decisión, el rector Arreguín declaró haber recibido el apoyo expreso del gobernador del estado a las medidas que las autoridades universitarias consideraran pertinente tomar para resolver el asunto. ${ }^{61}$

Tras conocerse la noticia de la expulsión, los alumnos afectados realizaron una reunión en uno de los salones del Colegio de San Nicolás, en la que desconocieron al CEN y nombraron una comisión, integrada por ocho alumnos, para que gestionara le fuera levantada la pena a los acusados. Esta comisión, atendiendo a sus funciones, dirigió un pliego petitorio al rector. En la reunión, en la que participaron casi un centenar de estudiantes, se constituyó el Frente Único de Solidaridad Estudiantil. Esta acción respondió a la consideración de que los estudiantes formaban una clase definida y que como tal estaban obligados a asumir una actitud de solidaridad en defensa de sus intereses. El Frente rechazó la expulsión de los acusados por considerarla una medida unilateral y señalaron que lo acontecido era el resultado de la inconformidad de los estudiantes con la organización universitaria. ${ }^{62}$

Por su parte, el rector se entrevistó con el presidente de la República y con el gobernador del estado a quienes informó sobre los acontecimientos y las decisiones tomadas, recibiendo de estos funcionarios la aprobación de las medidas dictadas y el ofrecimiento de ayudar a las autoridades universitarias en el caso en cuestión. ${ }^{63}$

Organizaciones de diverso tipo se expresaron a favor y en contra de las expulsiones decretadas. El Bloque Obrero y Campesino y el Bloque Sindical Unitario, de Morelia, ligados al Partido Comunista, el Comité contra el Fachismo y la Guerra; así como el Sindicato de Panaderos "Isaac Arriaga” y el Bloque Obrero y Campesino, de Puruándiro, Michoacán, enviaron notas de protesta por la expulsión de los acusados. Sin embargo, las autoridades universitarias desestimaron la validez de estos documentos al sospechar que habían sido redactados por los propios estudiantes. Las alumnas de la escuela secundaria anexa a la Normal también pidieron fuera cancelada la sanción a los acusados.

Los alumnos expulsados se reunieron con el rector para exponer su versión de los hechos y para solicitar fueran recibidos por el Consejo Universitario para ejercer su defensa y solicitar la revocación del acuerdo de expulsión. Por su parte, la dirigencia del CEN, al tiempo que apoyó las medidas adoptadas por las autoridades universitarias, pidió que las sanciones contra los acusados fueran reducidas al mínimo, para no dañarlos materialmente. El CEN propuso que se

61 "Acta de Consejo Universitario" (Morelia, 22 de mayo de 1935), AHUM, Consejo Universitario, Secretaría, Actas.

62 "Acta de Consejo Universitario" (Morelia, 6 de junio de 1935), (AHUM), Consejo Universitario, Secretaría, Actas.

63 "Acta de Consejo Universitario" (Morelia, 6 de junio de 1935), (AHUM), Consejo Universitario, Secretaría, Actas. 
levantara provisionalmente la sanción a los acusados a reserva de ratificarla el 20 de septiembre, de acuerdo con su conducta. ${ }^{64}$

Ante el Consejo Universitario, los acusados pidieron que se les hicieran cargos concretos y que se demostrara su culpabilidad en los actos cometidos. Los afectados pusieron en duda la capacidad legal de las autoridades universitarias para decretar las expulsiones, alegando que estas solamente constituían una medida represiva; asimismo, denunciaron que las investigaciones de los hechos habían sido violentas y que la lista de acusados no incluía a todos los participantes en los desórdenes. ${ }^{65}$

La expulsión de los estudiantes acusados de agitación derivó en problemas mayores para las autoridades universitarias. Los inconformes se dividieron en dos bandos. Algunos de los expulsados pidieron que se reconsiderara su sanción y alegaron no tener nexos con los comunistas; estos, por su parte, radicalizaron su posición. Entre los principales críticos de la administración universitaria se señaló a los estudiantes Millán y Bravo Baquero, quien a raíz de los hechos viajó a la Ciudad de México para buscar apoyo entre estudiantes y funcionarios de la Universidad Autónoma de México. ${ }^{66}$

Jesús Bravo Baquero fue un crítico de las administraciones universitarias de Jesús Díaz Barriga y Enrique Arreguín, a las que acusó de haber mezclado a la Universidad con la política y por haber utilizado a los estudiantes como elemento de presión política. En especial, criticó la "alumnocracia" generada por la Ley Orgánica universitaria de 1933 y su uso por parte de Enrique Arreguín con fines políticos. Sobre la actuación de Arreguín como secretario general de las Juventudes Socialistas de Michoacán, denunció que la organización estaba constituida por "camisas rojas" locales. En el campo doctrinario, Bravo Baquero fue uno de los principales críticos de la educación y la Universidad socialistas. Posteriormente señalaría que la base filosófica de la educación socialista no estuvo en el materialismo dialéctico, enemigo irreconciliable de todo idealismo, sino en una transacción ecléctica entre el materialismo y el idealismo de tipo positivista; esto en referencia a la necesidad, señalada en el artículo $3^{\text {o }}$ constitucional, de "crear en la juventud un concepto racional y exacto del universo" ${ }^{67}$

Poco tiempo después tuvieron lugar nuevas muestras de indisciplina. El 14 de agosto, un grupo de estudiantes realizó una manifestación en el Colegio de San Nicolás en la que intentaron quemar un "judas" con la figura del rector. Este objeto les fue arrebatado por el estudiante Alfonso Capilla, partidario de Arreguín, quien recibió una paliza que lo dejó inconsciente. ${ }^{68}$

En esta ocasión, los partidarios del rector Arreguín se movilizaron rápidamente. En los días siguientes, profesores y alumnos de las diferentes depen-

\footnotetext{
64 "Acta de Consejo Universitario" (Morelia, 6 de junio de 1935), (AHUM), Consejo Universitario, Secretaría, Actas.

65 "Acta de Consejo Universitario" (Morelia, 6 de junio de 1935), (AHUM), Consejo Universitario, Secretaría, Actas.

66 "Misiva de Enrique Arreguín a Jesús Díaz Barriga" (Morelia, 12 de junio de 1935), (APEAV), caja 28, exp. 2, ff. 472-473.

67 Jesús Bravo Baquero, El Movimiento Latinoamericano de Reforma Universitaria en Michoacán. La Universidad Michoacana en su primer cincuentenario, 1917-1967 (Morelia: UMSNH, 1978), 33, 39, 51.

68 Anónimo, “¿Qué hay en el bajo fondo del conflicto estudiantil en Morelia, Michoacán?”, Hombre Libre, México, 4 de septiembre, $1935,2-3$.
} 
dencias universitarias se dirigieron al presidente de la República para protestar por los hechos y para pedir apoyo para las autoridades universitarias y las medidas que estas tomaran contra los causantes de los desórdenes. Estudiantes y profesores denunciaron que un grupo de universitarios, haciéndose pasar por comunistas, se habían dedicado a insultar al Gobierno de la República y a sus funcionarios; además, ese mismo grupo de estudiantes se había dedicado a promover actos de indisciplina y a atacar sistemáticamente a las autoridades universitarias. Los disidentes fueron acusados de "antirrevolucionarios", de intentar cambiar el orden universitario para seguir el ejemplo de la Universidad Autónoma de México y de criticar la posición de la Universidad Michoacana en sus relaciones con el Estado. ${ }^{69}$

A pesar de las muestras de desaprobación hacia su gestión, Enrique Arreguín se mantuvo al frente de la Universidad hasta finalizar el año de 1935. Durante este lapso, la institución creció al amparo de las autoridades estatales y federales que vieron en los universitarios michoacanos un aliado en la puesta en práctica de sus proyectos educativos. La labor de Enrique Arreguín al frente de la Universidad Michoacana fue distinguida con una invitación a integrarse al recién formado Consejo Nacional de la Educación Superior y la Investigación Científica, organismo del que fue nombrado miembro el $1^{\circ}$ de enero de $1936 .{ }^{70}$

A su salida de la Universidad Michoacana, Enrique Arreguín dejaría una honda impresión entre los partidarios de la Universidad socialista. Al igual que Jesús Díaz Barriga, Arreguín se convertiría en un punto de referencia para muchos de los universitarios en los años posteriores y, desde la Ciudad de México, seguiría trabajando como enlace entre la Universidad Michoacana y las autoridades educativas federales y la Presidencia de la República.

Por otra parte, a la par de la simpatía que despertó el proyecto de Universidad socialista entre las autoridades estatales y federales, las pretensiones socializantes de los universitarios michoacanos motivaron críticas en puntos opuestos del espectro político. Los socialistas más radicales y los comunistas no ocultaron sus dudas sobre el verdadero alcance y naturaleza de un "socialismo" promovido por el Estado. Comunistas y católicos coincidieron en criticar a Arreguín por sus antecedentes "típicamente burgueses" y lo acusaron de vivir en la opulencia al tiempo que hablaba de trabajar en beneficio del proletariado. Para algunos, los errores de la administración universitaria, así como sus alardes de radicalismo, fueron los elementos que motivaron las desordenadas manifestaciones de protesta de sus detractores. ${ }^{71}$

69 "Telegrama de un grupo de alumnos de la Facultad de Medicina de la Universidad Michoacana al presidente de la República" (Morelia, 15 de agosto de 1935). "Memorial de profesores de la Escuela de Comercio y Administración al presidente de la República" (Morelia, 15 de agosto de 1935). "Telegrama de la Sociedad de Alumnos de la Casa del Estudiante Nicolaita al presidente de la República" (Morelia, 16 de agosto de 1935). "Comunicación de un grupo de profesores del Colegio de San Nicolás al presidente de la República” (Morelia, 17 de agosto de 1935), (AGN), LCR, caja 745, exp. 534.8/3. "Telegrama de un grupo de alumnos del Colegio de San Nicolás al presidente de la República" (Morelia, 16 de agosto de 1935), (AGN), LCR, caja 692, exp. 534.1/92.

70 "Nombramiento de Enrique Arreguín como miembro del CNESIC", (APEAV), caja 18, exp. 2, f. 150.

71 Anónimo, "Qué hay en el bajo fondo del conflicto estudiantil en Morelia, Michoacán", Hombre Libre, México, 4 de septiembre, 1935, $2-3$. 
De acuerdo con los impugnadores del rector Arreguín, la Universidad estaba en manos de personas incapaces de satisfacer las exigencias de la nueva enseñanza; la institución estaba controlada por una camarilla de privilegiados y se carecía de un programa de acción universitaria. También se denunció la división existente entre el estudiantado y se acusó a los dirigentes universitarios de utilizar a la institución como escalón para alcanzar puestos públicos; a todo esto, se sumaron las quejas por la injusta distribución de las becas y por la incapacidad de algunos maestros. ${ }^{72}$ Incluso entre los universitarios y autoridades del gobierno del estado, la gestión de Enrique Arreguín fue señalada, como en su momento sucedió con la de Jesús Díaz Barriga, como un periodo de relajación de la disciplina, reflejada en los tumultos estudiantiles y en las manifestaciones de hostilidad en contra de la autoridad de los profesores. Según algunas opiniones, los alumnos se dedicaban más a hacer política que a atender sus deberes estudiantiles. $^{73}$

\section{CONCLUSIÓN}

El proyecto de socializar la educación superior en Michoacán coincidió con un marco general de ideas que estaba presente en diferentes ámbitos de la vida nacional. Las alusiones a la "doctrina socialista", con todo lo que esta idea podía implicar, fueron una constante en el debate político e ideológico que acompañó a la redacción del Plan Sexenal de 1933, a la campaña presidencial de Lázaro Cárdenas y a la reforma del artículo $3^{\circ}$ constitucional de $1934 .{ }^{74}$ Durante la campaña presidencial, el Partido Nacional Estudiantil Pro Cárdenas y otras organizaciones del estudiantado nicolaita realizaron una labor de difusión de la "doctrina socialista", que se decía encauzaría la obra social de régimen cardenista. Los difusores de estas ideas coincidieron en señalar al socialismo como la única vía para que la Revolución cumpliera con su programa y objetivos; al tiempo que hacían una crítica al liberalismo por su carácter individualista y trataban de establecer las diferencias entre el movimiento socialista mexicano y las posturas comunistas, en especial las que representaba la Unión Soviética. ${ }^{75}$

Enrique Arreguín Vélez, con el apoyo del presidente de la República, dio continuidad, radicalizándolo, al proyecto universitario promovido por Jesús Díaz Barriga una década antes. El joven rector, que pasó de ser un líder estudiantil a la

72 Miguel Estrada Iturbide, “Un comentario", Reconstrucción, Morelia, 14 de diciembre, 1935, 2-3.

73 "Informe de gobierno que rinde el general de división Gildardo Magaña, en el año de 1937" (Morelia, 16 de septiembre de 1937), Archivo Histórico del Congreso del Estado de Michoacán de Ocampo (AHCEMO), XLVI Legislatura, varios, caja 3, exp. 5.

74 La falta de precisión del término "socialista" en el artículo $3^{\circ}$ reformado, así como las declaraciones de algunos funcionarios y autoridades del PNR y del Gobierno de la República que se refirieron con frecuencia al "socialismo de la Revolución Mexicana", causaron confusión sobre el sentido del vocablo. Sin embargo, tanto las organizaciones estudiantiles, obreras y magisteriales que propusieron la reforma, como las deliberaciones en el PNR y las asambleas de la Cámara, dejaron claro que se trataba de un "socialismo científico". Véase: Alberto Bremauntz, La educación socialista en México (México: Imprenta Rivadeneyra, 1943), 228-229, 356. Engracia Loyo, "La difusión del marxismo y la educación socialista en México, 1930-1940", en Cincuenta años de historia en México, vol. 2, eds. Alicia Hernández Chávez y Manuel Miño (México: El Colegio de México, 1991), 175.

75 Adolfo Gilly, "Los dos socialismos mexicanos", en El nacionalismo en México, eds. Cecilia Noriega Elío (Zamora: El Colegio de Michoacán, 1992), 358-359. 
rectoría universitaria, siguió como plan de trabajo uno que había esbozado desde sus años de dirigente en el CEN y el BJRM. Estas, como otras organizaciones similares, fueron las principales promotoras del reformismo universitario socialista. Sus vínculos con las principales fuerzas políticas del país, principalmente el partido oficial, les garantizaron un amplio margen de acción y prerrogativas para imponer su dominio sobre el estudiantado nicolaita y extenderlo hacia el gobierno de la Universidad.

El radicalismo socialista fue moderado por las líneas de acción marcadas por el proyecto político cardenista. El laicismo, el anticlericalismo, la socialización de la educación y de las profesiones, el papel rector del Estado, fueron postulados asumidos y defendidos por los universitarios michoacanos. En el contexto político de los años veinte y treinta cumplieron satisfactoriamente con esta tarea, lo que reportó beneficios para su propio proyecto universitario. El radicalismo de los universitarios cardenistas nunca puso en entredicho el poder del Estado. Su función fue la de profundizar y acelerar la implementación de un proyecto político. Además, cumplieron una función estratégica al combatir sistemáticamente a sus adversarios ideológicos y políticos. Las purgas ideológicas y el control de las organizaciones estudiantiles fueron muestra de ello.

Los vínculos establecidos entre los universitarios socialistas y el cardenismo permitieron a los primeros participar del poder, pero también los convirtió en objeto de críticas por parte de sectores de diferente signo ideológico que impugnaban la política educativa oficial. El proyecto de Universidad socialista fue criticado tanto por católicos como por comunistas y socialistas radicales que no veían satisfechos sus intereses en el proceso de reforma que estaba experimentando la institución.

\section{FUENTES}

Archivo General de la Nación (AGN), Ciudad de México-México. Lázaro Cárdenas del Río (LCR). Archivo Histórico de la Universidad Michoacana (AHUM), Morelia-México. Consejo Universitario, Educación Preparatoria, Educación Profesional, Universidad Michoacana de San Nicolás de Hidalgo (UMSNH).

Archivo del Centro de Estudios sobre la Revolución Mexicana "Lázaro Cárdenas" (ACERMLC), Jiquilpan-México. Francisco J. Múgica (FJM).

Archivo Histórico del Congreso del Estado de Michoacán de Ocampo (AHCEMO), Morelia-México. XLVI Legislatura.

Archivo Particular de Enrique Arreguín Vélez (APEAV), Zamora-México.

Anónimo, “Congreso de estudiantes. El Bloque de Jóvenes Revolucionarios Michoacanos lo celebra en Morelia", El Nacional, México, 26 de abril, 1935.

Anónimo, “Decreto por el que se destina al servicio del Gobierno del Estado, el predio número 580 de la Avenida Madero, en Morelia, Michoacán", Diario Oficial, México, 1o de febrero, 1935.

Anónimo, "El 'Centro Cultural Obrero' fue inaugurado en la ex Escuela Libre de Michoacán”, El Nacional, México, 10 de febrero, 1935.

Anónimo, "El deber de la Universidad", El Nacional, 23 de septiembre, 1934.

Anónimo, "Estatutos y programa de acción del Bloque de Jóvenes Revolucionarios de Michoacán", Gremio, Morelia, 20 de diciembre, 1934.

Anónimo, “La convención estudiantil empezó sus labores", Juventud, Morelia, 26 de agosto, 1932. 
Anónimo, "La Universidad debe dar sus frutos para el pueblo y no para la clase parasitaria. Memorial del Bloque de Jóvenes Revolucionarios Michoacanos a la Cámara", El Nacional, 22 de septiembre, 1934.

Anónimo, "Labor de la Universidad en 1935. La acción organizadora del Centro Cultural Obrero", El Nacional, México, 18 de enero, 1936.

Anónimo, "Las autoridades universitarias dicen que no hay dinero", Atalaya, Morelia, $1^{\underline{0}}$ de marzo, 1935.

Anónimo, "Michoacán inicia la educación socialista", Excelsior, 22 de septiembre, 1934.

Anónimo, "Nuevo rector", Gremio, Morelia, 20 de diciembre, 1934.

Anónimo, "Proyecto de Estatutos de la Unión de Estudiantes Socialistas de Michoacán presentada por la Comisión de Estatutos de la Convención Estudiantil", Juventud, Morelia, 26 de agosto, 1932.

Anónimo, "Qué hay en el bajo fondo del conflicto estudiantil en Morelia, Michoacán", Hombre Libre, México, 4 de septiembre, 1935.

Anónimo, "Se inauguró el II Congreso de Estudiantes Socialistas", El Nacional, México, 10 de octubre, 1935.

Anónimo, "Solemne inauguración de cursos en la Universidad. Fue delineado el programa a los trabajadores", brecha, Morelia, jueves 17 de enero, 1935.

Anónimo, "Solicitud de los estudiantes nicolaitas", Ariel, Morelia, 15 de mayo, 1926.

Anónimo, "Un centro cultural para obreros. Ha sido fundado por el rector de la Universidad Michoacana", brecha, Morelia, miércoles 9 de enero, 1935.

Anónimo, "Ya llegaron los libros a la Biblioteca del Colegio de San Nicolás", Atalaya, Morelia, $1^{\circ}$ de abril, 1935.

Miguel Estrada Iturbide, “Un comentario”, Reconstrucción, Morelia, 14 de diciembre, 1935.

Méndez Moreno, Carlos Domingo. "El Bloque de Jóvenes Revolucionarios de Michoacán y la política social cardenista". Tesis de maestría en, Universidad Michoacana de San Nicolás de Hidalgo, 2008.

\section{REFERENCIAS}

Anguiano Equihua, Victoriano. Lázaro Cárdenas. Su feudo y la política nacional. México: Editorial Referencias, 1989.

Arreguín Vélez, Enrique. Enrique Arreguín Vélez: su pensamiento y acción en la ciencia y en la cultura. Morelia: Universidad Michoacana de San Nicolás de Hidalgo, 1968.

Bravo Baquero, Jesús. El Movimiento Latinoamericano de Reforma Universitaria en Michoacán. La Universidad Michoacana en su primer cincuentenario, 1917-1967. Morelia: Universidad Michoacana de San Nicolás de Hidalgo, 1978.

Bremauntz, Alberto. La educación socialista en México. México: Imprenta Rivadeneyra, 1943.

Cárdenas, Lázaro. Palabras y documentos públicos de Lázaro Cárdenas, 1928-1970. Informes de gobierno y mensajes presidenciales de año nuevo, 1928-1940. México: Siglo XXI Editores, 1978.

Díaz Aldama, Hilda. Los estudios de jurisprudencia en la Universidad Michoacana, 1917-1932. Morelia: Universidad Michoacana de San Nicolás de Hidalgo, 2000.

Gilly, Adolfo. "Los dos socialismos mexicanos". En El nacionalismo en México, editado por Cecilia Noriega Elío. Zamora: El Colegio de Michoacán, 1992, 355-371.

Gutiérrez Martínez, Ángel, Lázaro Cárdenas y la Universidad Michoacana. Morelia: Universidad Michoacana de San Nicolás de Hidalgo, 2005.

Hernández Aragón, Ma. de la Paz. Juan Hernández Luna. Humanista nicolaita del siglo XX. Morelia: Universidad Michoacana de San Nicolás de Hidalgo, 2001.

Hernández Rodríguez, Rogelio. La formación del político mexicano. El caso de Carlos A. Madrazo. México: El Colegio de México, Universidad Juárez Autónoma de Tabasco, 1997.

Loyo, Engracia. "La difusión del marxismo y la educación socialista en México, 1930-1940". En Cincuenta años de historia en México, editado por Alicia Hernández Chávez y Manuel Miño. México: El Colegio de México, 1991, 165-181. 
Luna Flores, Adrián. La Universidad Michoacana: 1926-1932. El rectorado de Jesús Díaz Barriga. Morelia: Universidad Michoacana de San Nicolás de Hidalgo, 2002.

Macías, Pablo G. Aula Nobilis. México: Ediciones Vanguardia Nicolaita, 1940.

Méndez Moreno, Carlos Domingo. El anticlericalismo en Tabasco: entre prácticas, símbolos y representaciones. Morelia: Universidad Michoacana de San Nicolás de Hidalgo, 2016.

Oikión Solano, Verónica. Los hombres del poder en Michoacán, 1924-1962. Zamora: El Colegio de Michoacán, Universidad Michoacana de San Nicolás de Hidalgo, 2004.

Plan Sexenal del PNR. México: Partido Nacional Revolucionario, 1934.

Vizcaíno López, María Teresa. Universidad Michoacana de San Nicolás de Hidalgo: panorama jurídico, 1917-1939. Morelia: Universidad Michoacana de San Nicolás de Hidalgo, 2000.

\begin{tabular}{l|l|} 
& \\
\hline $\begin{array}{l}\text { Gutiérrez López, Miguel Ángel. “La reforma universitaria desde } \\
\text { el Estado y el radicalismo estudiantil nicolaita, 1926-1935”. Revista } \\
\text { Historiadela Educación Latinoamericana. Vol.20 No.30(2018):143-166. }\end{array}$ & \\
\hline &
\end{tabular}

